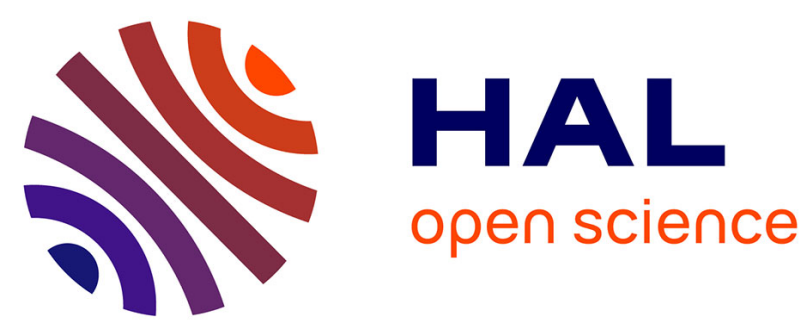

\title{
Investigating Dual Effects of Social Networking Sites
}

\author{
A. Najmul Islam, Matti Mäntymäki, Aaron W. Baur, Markus Bick
}

\section{To cite this version:}

A. Najmul Islam, Matti Mäntymäki, Aaron W. Baur, Markus Bick. Investigating Dual Effects of Social Networking Sites. 17th Conference on e-Business, e-Services and e-Society (I3E), Oct 2018, Kuwait City, Kuwait. pp.81-101, 10.1007/978-3-030-02131-3_10 . hal-02274179

HAL Id: hal-02274179

https://hal.inria.fr/hal-02274179

Submitted on 29 Aug 2019

HAL is a multi-disciplinary open access archive for the deposit and dissemination of scientific research documents, whether they are published or not. The documents may come from teaching and research institutions in France or abroad, or from public or private research centers.
L'archive ouverte pluridisciplinaire HAL, est destinée au dépôt et à la diffusion de documents scientifiques de niveau recherche, publiés ou non, émanant des établissements d'enseignement et de recherche français ou étrangers, des laboratoires publics ou privés. 


\title{
Investigating Dual Effects of Social Networking Sites
}

\author{
A.K.M. Najmul Islam ${ }^{[1]}$, Matti Mäntymäki ${ }^{[1]}$, Aaron W. Baur ${ }^{[2]}$, and Markus Bick ${ }^{[2]}$ \\ ${ }^{1}$ Turku School of Economics, University of Turku, Turku, Finland \\ \{najmul.islam,matti.mantymaki\}@utu.fi \\ ${ }^{2}$ ESCP Europe Business School Berlin, Berlin, Germany \\ \{abaur, mbick\} @escpeurope.eu
}

\begin{abstract}
This paper investigates the dual effects (i.e. benefits and dangers) of a social networking site (SNS). Our dependent variables are subjective vitality and addiction. We employ self-determination theory (SDT), specifically the concepts of autonomous and controlled motivation and hypothesize that social enhancement and enjoyment represent autonomous motivation and contributes to subjective vitality while voyeurism and exhibitionism represent controlled motivation and contribute to SNS addiction. We test our hypotheses with data from 289 student Facebook users using Partial Least Squares (PLS). The results suggest that both social enhancement and enjoyment predict subjective vitality. In contrast, exhibitionism is the sole predictor of SNS addiction while voyeurism has no effect.
\end{abstract}

Keywords: Social networking sites, Addiction, SNS Addiction, Subjective Vitality, Voyeurism, Exhibitionism, Enjoyment

\section{$1 \quad$ Introduction}

Social networking sites (SNSs) have become a prominent venue for social interaction. Nearly $80 \%$ of the Internet users use social networking sites such as Facebook, the Russian vKontakte or the Chinese equivalent Renren. The most popular SNS, Facebook, has more than 2 billion users globally.

SNSs offer their users various ways for communication, social interaction and selfpresentation (Mäntymäki \& Islam, 2014; 2016). Good social relationships and interaction with other people support one's psychological well-being. Considering the number of SNS users globally, it is particularly interesting to investigate to what extent SNS use supports user's psychological well-being (Islam et al., In Press). For example, receiving positive feedbacks on posted content may increase an individual's self-esteem and well-being (Valkenburg et al., 2006).

The IS research is traditionally emphasized performance improvement as the main benefit of IT use (Davis, 1989; DeLone \& McLean, 2003; Venkatesh et al., 2012). The performance improvement has traditionally been conceptualized as (work) efficiency gains. In addition, due to the proliferation of hedonic IS and consumer use of IT the hedonic outcomes have gained increasing interest (Turel \& Serenko, 2012; Van der Heijden, 2004; Venkatesh et al., 2012). 
However, individual's psychological well-being as an outcome of IT use, particularly in the SNS context, has thus far received only limited attention in prior IS research. To fill this research gap, we explore what increases individuals' subjective vitality (i.e., an aspect of well-being) in an SNS use context. In practice, we argue that social enhancement and enjoyment are the two drivers of subjective vitality.

At the same time, there is an increasing awareness that the accelerated sharing caused by the pervasive use of social networking sites is not entirely positive but is also related to adverse phenomena such as voyeurism, exhibitionism (Munar, 2010), and addiction (Andreassen et al., 2012). Prior IS research suggested that hedonic systems like SNSs, games, etc. would be more addictive than utilitarian system (Turel \& Serenko, 2012). In general, technology producing thrills or filling socio-psychological voids in users' lives are more addictive than others (Young, 2010). By participating in an SNS, an individual fills his/her social voids and experiences thrills, and thus he/she becomes addicted to the SNS (Turel \& Serenko, 2012).

Turel \& Serenko (2012) found that majority of prior technology addiction research investigated the consequences of technology addiction. Technology addiction can affect adversely on individual, organizational, and societal levels. Possible technology addiction outcomes include productivity losses (Yellowless \& Marks, 2007), health problems (Block, 2008), worsening academic performance (Kuss \& Griffiths, 2011), and additional treatment costs (Xu et al., 2012). There is a lack of research on understanding antecedents/determinants of technology addiction (Turel \& Serenko, 2012). To fill this second research gap, we explore factors that might contribute to SNS addiction. As a result, we place voyeurism and exhibitionism motivations as factors driving SNS addiction.

To recap, SNS use can bring both benefits and dangers to the users. Therefore, this paper examines the dual effect of SNS use. In doing so, we extend the scope of IS research from examining only either benefits (DeLone \& McLean, 2003; Venkatesh et al., 2012) or dangers (Turel et al., 2011; Xu et al., 2012) towards a parallel investigation of both positive and negative side of IT use (Mäntymäki \& Islam, 2016).

The remainder of this paper is organized as follows. In section 2 we present the theoretical foundations. Section 3 is dedicated to hypotheses development and section 4 presents the research method. Section 5 presents data analysis results and discussions. Finally, section 6 discusses limitations and future research.

\section{Theoretical Foundations}

\subsection{Subjective Vitality}

The concept of vitality has been theorized as an important idea within diverse theoretical frameworks (Ryan \& Deci, 2008). According to the Oxford English Dictionary, an individual with vitality has vigour and liveliness, a general energy for life. When vital, individuals experience a sense of enthusiasm, aliveness, and energy available to the self (Ryan \& Fredrick, 1997).

As one cannot, in principle, directly measure the energy available to the self, Ryan \& Fredrick (1997) suggested exploring vitality as a subjective variable. In relation to 
this, Akin (2012) defined subjective vitality as the subjective experience of being full of energy and alive. Furthermore, subjective vitality is considered as an aspect of eudaimonic well-being, as being vital and energetic is part of what it means to be fully functioning and psychologically well (Ryan \& Deci, 2001).

Prior research on psychology and medicine has empirically found that subjective vitality is robustly associated with both behavioural and health outcomes (e.g., Pennix et al., 2000; Ryan \& Deci, 2008; Thayer, 1996). This assertion has been supported by neuroscientific research that has shown that when experiencing vitality, specific configurations in the brain are activated (Barrett et al., 2004). Consequently, subjective vitality has been linked to other positively toned and energized states such as feelings of vigour (McNair et al., 1971), calm energy (Thayer, 1996), and activated positive affect (Watson \& Tellegen, 1985). Vital individuals have been found more active and productive and possess better abilities to cope with stress and challenges (Ryan \& Deci, 2008). In addition, vital individuals are less vulnerable to illness, have better mental health as well as are more resilient to physical and viral stressors (Pennix et al., 2000; Ryan \& Deci, 2008).

Ryan \& Deci (2008) argued subjective vitality as a complex and dynamic outcome that is influenced by social and psychological factors. They pointed that social events could leave even a well-nourished person feeling excited and energized, or alternatively stressed, angelic, and drained. As SNSs have become an integral part of people's social life, it is important for IS researchers to investigate what factors influence individual's subjective vitality in the SNS use context.

Prior psychology literature conceptualized subjective vitality in two ways: individual difference level (Ryan \& Frederick, 1997) and state level (Nix et al., 1999). In this paper, we have adopted the state level conceptualization of subjective vitality (i.e., the energy felt during SNS use). Consequently, we define subjective vitality as the subjective experience of being full of energy and alive during SNS use.

Although the concept of subjective vitality has never been explored in IS research, we argue that it can be linked to several IS constructs. We suggest two research directions for IS researchers related to subjective vitality. First, IS researchers may explore the outcomes of subjective vitality. For example, subjective vitality may improve individuals' productivity in an organization, and ability to innovate with IT. Second, examining the antecedents of subjective vitality such as design features of the IT artifact or user motivation would be meaningful for IS researchers.

\section{$2.2 \quad$ Addiction}

The concept of addiction is frequently used in clinical and behavioural science (Marlatt et al., 1988). Addiction is defined as a repetitive habit pattern that increases the risk of disease and/or associated personal and social problems, often experienced subjectively as "loss of control" [that] continues despite volitional attempts to abstain or moderate use (Marlatt et al., 1988, p. 224). 
Addiction has six symptoms as suggested by prior literature (Brown, 1993; Griffiths, 2005; Andreassen et al., 2012). These are: (1) Salience: meaning that the activity dominates thinking and behaviour; (2) Mood modification: meaning that the activity modifies/improves mood; (3) Tolerance: meaning that an increasing amount of activity is required for the purpose of remaining satisfied; (4) Withdrawal: meaning that when the activity is discontinued or suddenly reduced, the individual experiences panic, anxiety, agitation, or other unpleasant feelings; (5) Conflict: meaning that the activity causes conflicts in relationships, in work/studies, and other activities; (6) Relapse: meaning that the tendency to revert to earlier patterns of the activity after abstinence or control.

Since the early 1990s, psychology researchers have been investigating the phenomenon of technology dependencies or technology addictions (Kubey \& Csikszentmihalyi, 2002). Technology addictions are a type of behavioural addiction that does not involve any external chemical substance (Marks, 1990). These addictions mainly occur when human interacts with machines (Widyanto \& Griffiths, 2006). They can be classified either as passive (e.g., radios, televisions, etc.) or active (e.g., computer games, Internet, online forums, SNSs, etc.), and include inducing and reinforcing features which may contribute to promote addictive tendencies (Griffiths, 1995). This implies that Internet addiction or problematic use of the Internet can be viewed as a type of active technology addictions. Internet addictions like other behavioural addictions are often manifested through the six symptoms (salience, mood modification, tolerance, withdrawal, conflict, and relapse) that have been described above.

In psychology and clinical psychology (Andreassen et al., 2012; Cheung et al., 2013), SNS addiction falls under the broad category of problematic use of the Internet. Diverse terminologies have been used in prior literature in order to refer problematic use of the Internet such as "Internet Addiction Disorder", "Pathological Internet Use", "Problematic Internet Use", "Excessive Internet Use", "Compulsive Internet Use", Cyberspace Addiction, Online Addiction, Net Addiction, Internet Addicted Disorder, and High Internet Dependency (Widyanto \& Griffiths, 2006; Douglas et al., 2008, Cheung et al., 2013). Altogether, as pointed out by Turel et al. (2011), the issue of problematic use of IT is relatively new in the IS literature, and scientific understanding of this issue is still evolving.

Young (1996) conducted the first ground-breaking research study on the problematic use of Internet. Following this, several researchers defined Internet addiction. For example, Mitchell (2000, p. 632) defines Internet Addiction Disorder as "the compulsive overuse of the Internet and the irritable or moody behaviour when deprived of it". Rice (2005) defined Internet Addiction as a proclivity toward compulsive use of the Internet that interferes with one's ability to lead a normal life. Shapira et al. (2003) conceptualized problematic Internet use as an impulse control disorder in which an individual experiences rising tension or arousal before Internet use and a sense of relief or pleasure after completion of the behaviour. Internet addiction is characterized by one's inability to control his/her dependence on the Internet, leading to feelings of distress and functional impairments of daily activities (Shapira et al., 2000). Beard (2005) defined it as an individual's psychological state, which includes both mental and emotional states, as well as their scholastic, occupational and social interactions, is impaired by the overuse of the medium. 
To sum up, all these definitions capture one or more symptoms of behavioural addictions. This accords with the suggestions to conceptualize addiction using six core symptoms of behavioural addictions (e.g., Charlton \& Danforth, 2007; Davis et al., 2002; Young, 1998). Following this, we conceptualize SNS addiction as the degree of a user's psychological dependency on the SNS, and the magnitude of the associated behavioural addiction symptoms.

\subsection{Motivations}

\section{Social enhancement}

Social enhancement is the value that an individual derives from gaining acceptance and approval from other SNS members, and the enhancement of one's social status within his/her community (Dholakia et al., 2004). Building one's accurate perceptions of the self is important for his future mental health (Taylor \& Brown, 1989). Individuals generally want to see themselves and be seen by others in a positive light, and thus they employ different strategies to enhance their social image (McCaslin et al., 2010). Recognition from others has been found as one of the driving forces behind joining virtual communities (Hars \& Ou, 2002).

Horvath \& Morf (2010) argued that narcissists and genuine self-esteemed individuals follow different strategies for social enhancement. Narcissists exploit self-enhancement opportunities primarily by augmenting self-ratings on positive traits while nonnarcissists self-present themselves more moderately and use more socially accepted discounting of negative traits. In this paper, we conceptualize social enhancement as a non-narcissistic tendency to present accurate image of oneself in an SNS platform.

Prior IS research has successfully used the concept of image, a variable similar to social enhancement (Moore \& Benbasat, 1991; Venkatesh \& Davis, 2000). It has been found that individuals' technology usage behaviour is motivated by image (e.g., Venkatesh \& Davis, 2000).

\section{Hedonic motivation}

Due to the advent of systems such as computer and console games, virtual worlds and SNSs, hedonic uses of IS have become increasingly important. Hedonic systems aim to provide self-fulfilling values such as fun, and pleasure to the users. Hence, the focus on motivational drivers of system use has shifted from extrinsic to intrinsic reflections, such as perceived enjoyment (Van der Heijden, 2004; Turel \& Serenko, 2012). Intrinsic motivation refers to the activity spawned by the pleasure of action (Ryan \& Frederick, 1997) and drives voluntary activity done for no apparent reinforcement other than the process of performing the activity per se (de Charms, 1968).

Prior IS literature has successfully used the concept of intrinsic motivation. Venkatesh (2000) found intrinsic motives are important for system use decisions. Van der Heijden (2004) even found perceived enjoyment (i.e., an intrinsic motivation) as more important than perceived usefulness in predicting intention to use hedonic systems. Perceived enjoyment was also found important predicting habit and engagement in SNS usage context (Turel \& Serenko, 2012). Based on these findings, we decided to use 
perceived enjoyment as the proxy of hedonic motivation. We conceptualize perceived enjoyment as the extent to which the activity of using an SNS is perceived to be enjoyable in its own right (Davis et al., 1992).

\section{Voyeurism}

Traditionally, the concept of voyeurism has referred to the sexual interest in or practice of spying on people who are naked or who are engaged in sexual activities, or other actions that are usually considered private in nature (Hirschfeld, 1938).

The most extreme behavioural manifestations of voyeurism are clinically regarded as abnormal sexual behaviour. American Psychiatric Association's (APA) Diagnostic and Statistical Manual of Mental Disorders (DSM-IV, 1994) offers the following psychiatric diagnostic criteria for voyeurism:

A. Over a period of at least 6 months, recurrent, intense sexually arousing fantasies, sexual urges, or behaviors involving the act of observing an unsuspecting person who is naked, in the process of disrobing, or engaging in sexual activity.

B. The person has acted on these sexual urges, or the sexual urges or fantasies cause marked distress or interpersonal difficulty.

Today, as pointed out by Calvert (2009), voyeurism does not necessarily include sexuality. In the context of media use, Calvert $(2009$, p. 2) defines voyeurism as "the consumption of revealing images of and information about other's apparently real and unguarded lives, often yet not always for purposes of entertainment but frequently at the expense of privacy and disclosure, through the mass media and Internet." Many everyday activities such as watching reality TV can be driven by voyeuristic motives without any sexual connotation. In this paper, we conceptualize voyeurism as pleasure derived by accessing others' private content in SNSs (Metzl, 2004).

\section{Exhibitionism}

Exhibitionism refers to self-disclosure "process of making the self, known to others" (Jourard \& Lasakow, 1958, p. 91). With regard to exhibitionism, the self-disclosure is not driven by building trust to develop interpersonal relationships (see e.g. Joinson et al., 2008). Rather, the self-disclosure is driven by one's narcissistic tendency (Ames et al., 2006; Brunell et al., 2011; Carpenter, 2012) to demonstrate superiority and to seek for admiration from other people in order to build a desirable self-image. To this end, Oxford English Dictionary defines exhibitionism as an extravagant behaviour that is intended to attract attention to oneself and Webster's Ninth Collegiate Dictionary defines it as the act of practice of behaving so as to attract attention to oneself.

As a psychological trait in the general population, exhibitionism is not overtly negative or harmful like for example manipulation of others or hostility. Rather, it indicates extraversion and low impulse control (Panek et al., 2013). Furthermore, exhibitionism is considered as a first order-component of narcissistic personality (Ames et al., 2006; Raskin \& Terry, 1988). A combination of self-absorption, vanity, superiority, and exhibitionistic tendencies that illustrates the features of self-love and theatrical selfpresentation is labeled grandiose exhibitionism (Ackerman et al., 2011). 
Exhibitionism is diagnosed with the following criteria (DSM-IV, 1994):

A. Over a period of at least 6 months, recurrent, intense sexually arousing fantasies, sexual urges, or behaviours involving the exposure of one's genitals to an unsuspecting stranger.

B. The fantasies, sexual urges, or behaviours cause clinically significant distress or impairment in social, occupational, or other important areas of functioning.

People's self-disclosure in SNSs can be driven by exhibitionism as a narcissistic trait (Carpenter, 2012). In this paper, we do not consider exhibitionism as a psychopathological condition but conceptualize it as a pleasure derived from disclosing private information online in order to gain superiority.

\section{$3 \quad$ Hypotheses Development}

\subsection{The Bright Side: Social enhancement and perceived enjoyment as predictors of subjective vitality}

Prior psychology research differentiated between autonomous and controlled motivations (Ryan \& Frederick, 1997). An individual can be motivated to act in a particular way by external compulsion (i.e., controlled motivations) or out of inwardly endorsed motives such as personal interests or values (i.e., autonomous motivations). Intrinsic motivations have been regarded as autonomous by definition, which means that they are experienced as emanating from one's self, whereas extrinsic motivations vary in the degree to which they are autonomous versus controlled (Deci \& Ryan, 1991).

We argue that social enhancement and hedonic motivations are autonomous. Actions for enhancing social status and enjoyment in SNSs are self-determined. Koopmans \& Sremac (2011) pointed that presenting authentic self is autonomous. Based on this, it is logical to assume that the act of enhancing self or building one's appropriate image is autonomous. Prior IS research also suggested enjoyment as an intrinsic motivation (Van der Heijden, 2004) and hence it is autonomous by definition (Ryan \& Frederick, 1997). Individuals act with an internal perceived locus of causality in SNSs in order to gain social enhancement, and enjoyment (Deci \& Ryan, 1991).

When people are intrinsically motivated or autonomously extrinsically motivated, they will feel their energy enhanced (Nix et al., 1999). Consequently, it is logical to assume that social enhancement and enjoyment may enhance an individual's subjective vitality. Based on this we propose the following two hypotheses.

\section{H1. Social enhancement positively influences subjective vitality}

\section{H2. Enjoyment positively influences subjective vitality}

We also argue that the other two motivations: exhibitionism and voyeurism are controlled motivations and hence these would not have any influence on subjective vitality. Voyeuristic people look for content that they cannot otherwise see in an SNS. These people do so due to their curiosity or comparing themselves with others to maintain self-esteem. Exhibitionist people look for opportunities to show that they are superior 
to others by presenting a possible self-image in an SNS. They do such activities because of a pressure to maintain self-esteem. Both voyeuristic and exhibitionistic behaviours are governed by a regulatory process within an individual that is experienced as a pressure or demand. Prior psychology research suggests that behaviours that are executed because of pressure or demand are controlled in nature (Nix et al., 1999). Thus, exhibitionism and voyeurism are controlled form of behaving and are not likely to enhance subjective vitality (Deci \& Ryan, 1991).

\subsection{The Dark Side: Voyeurism and exhibitionism as predictors of addiction}

Prior psychiatric literature suggests that exhibitionism and voyeurism are addictive sexual behaviours (Coleman-Kennedy \& Pendley, 2002; Roller, 2004). Following this, we argue that the exhibitionistic and voyeuristic motivations would make individuals addicted to the SNS.

Prior IS research on addiction suggests that excessive use of IS may develop habit which eventually lead to addiction (Turel \& Serenko, 2012). Following this finding, we argue that voyeuristic and exhibitionistic individuals use SNSs heavily and thus these people become addicted. The logical basis of this argument is that voyeurism cannot exist without disclosure whereas exhibitionists require an audience. Both types of individuals depend on each other (i.e., control each other) in an SNS platform. Both types of individuals require acceptance from each other to raise their self-esteem (Silverstein, 1996). In the process of gaining acceptance from others, exhibitionistic people spend huge amount of time to constantly post contents while voyeuristic people spend huge amount of time to constantly consume contents posted by others. Eventually, many people start to post contents publicly over real friends (Kuss \& Griffiths, 2012). Similarly, many individuals start to consume contents of unknown people. Spending hours in an SNS can lead to significant behavioural and psychological problems. For instance, they might feel a compulsion to use the SNS to meet their exhibitionistic and voyeuristic needs. Consequently, we propose the following two hypotheses.

\section{H3. Voyeurism positively influences addiction to SNS}

\section{H4. Exhibitionism positively influences addiction to SNS}

We also argue that the autonomous motivations: social enhancement and enjoyment are not expected to influence addiction. Addictive behaviours are compulsive. It means that an addict performs his addictive behaviour because he experiences an irresistible urge to do it. The addict performs the act repeatedly and unable to stop it. The act is not something that the addict does out of his/her self-choice. This implies that autonomous motivations are not expected to influence addiction. Koopmans \& Sremac (2011) pointed that addiction might be incompatible with autonomy as addiction is often been equated with loss of control, powerlessness, and unmanageability. 


\subsection{Controlling for habit}

Prior IS literature found habit (i.e., the extent to which people tend to perform behaviours automatically because of learning) as a significant determinant of addiction (Turel $\&$ Serenko, 2012). Consequently, we decided to control the effect of habit on addiction and subjective vitality in this paper. Figure 1 below summarizes the hypothesized relationships.

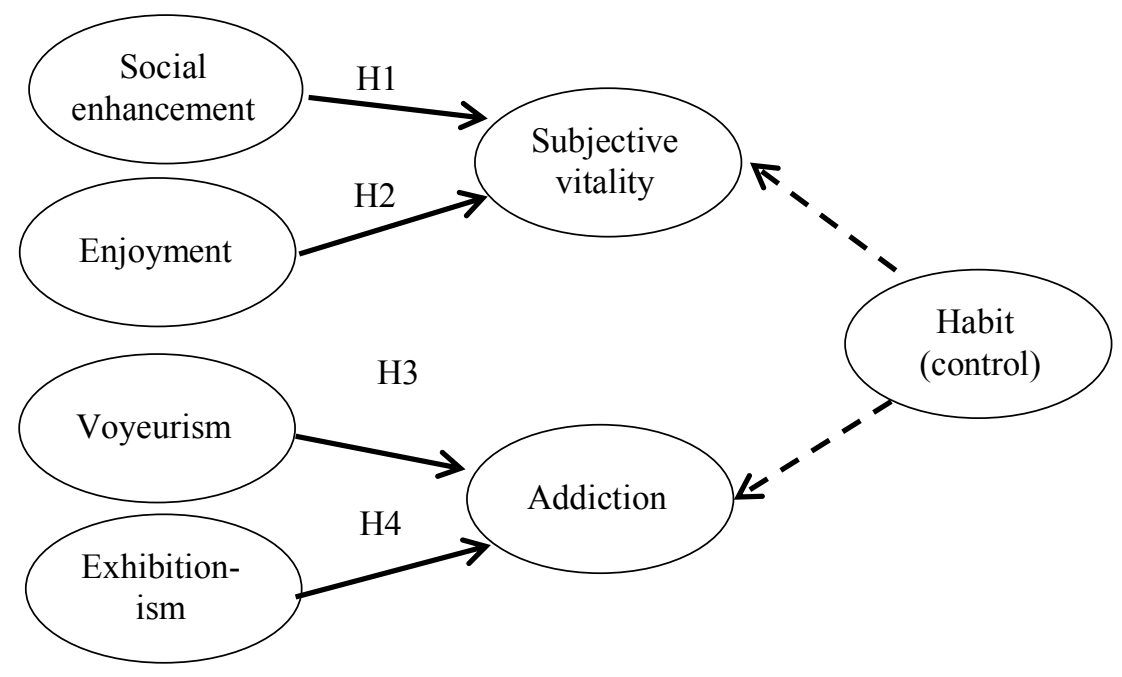

Fig. 1. The research model

\section{$4 \quad$ Study design}

\subsection{Instrument development}

The items were measured using five-point Likert scale, with answer choices ranging from "Strongly disagree (1)" to "Strongly agree (5)". Items were adopted from the prior literature with minor changes in wording reflecting the target context. The measures of habit were adapted from Limayem et al. (2007). The measures of social enhancement and enjoyment were adapted from Dholakia et al. (2004) and Davis et al. (1992) respectively. The measures of exhibitionism were adapted from Ames et al. (2006) while the measures of voyeurism were adapted from Nabi et al. (2006) and Bagdasarov et al. (2010). Finally, the measures of subjective vitality and addiction to SNS were adapted from Bostic et al. (2010) and Andreassen et al. (2012) respectively.

After the questionnaire was drafted, it was first sent to two senior scholars for a review. Based on their comments, some items were adjusted to make the wordings more precise. The final questionnaire items are shown in Table 1. 


\subsection{Data collection}

The data was collected with an online survey among student of a Finnish university. The respondents were randomly selected from a sample that in turn was randomly selected from student database. The survey was sent to altogether 1,500 respondents. Altogether 289 usable responses were received. This yielded to a response rate of 19.27 per cent. $68 \%$ of the respondents were female.

To investigate the possible non-respondent bias, we ran a series of independent samples t-tests. The respondents were first divided into two groups based on the median date of completion of the survey and then compared their responses on subjective vitality, addiction, habit, social enhancement, voyeurism, exhibitionism and enjoyment (Armstrong \& Overton, 1977). The test did not reveal any statistically significant differences between the early and late responses, supporting the notion that non-response bias was not a major concern in our study.

\subsection{Data analysis}

Partial least squares (PLS) approach with WarpPLS was utilized in the analysis. PLS is a second-generation regression method that combines confirmatory factor analysis with linear regression, and this makes it possible to run the measurement and structural models simultaneously. A rule of thumb for the required sample size in PLS is that the sample should be at least ten times the most complicated multiple regressions in the model (Barclay et al., 1995). The sample size in this paper fulfils this criterion well.

We followed Gefen and Straub's (2005) procedure to test convergent and discriminant validity. Convergent validity indicates the extent to which the items of a scale that are theoretically related are also related in reality. Convergent validity is ensured by comparing the item loadings, composite reliability (CR), and average variance extracted (AVE) values. Fornell and Larcker (1981) recommended path-loading values at least 0.7 to be acceptable. Based on this criterion, SV2 from subjective vitality construct was removed. Similarly, ADDICT3, and ADDICT4 have been removed from addiction construct. From Table 2, we observe that all the constructs have composite reliability values between 0.855 and 0.920 , fulfilling the recommended value proposed by Nunnally (1978). Finally, all AVE values exceed the threshold of 0.5 as recommended by Fornell and Larcker (1981). 


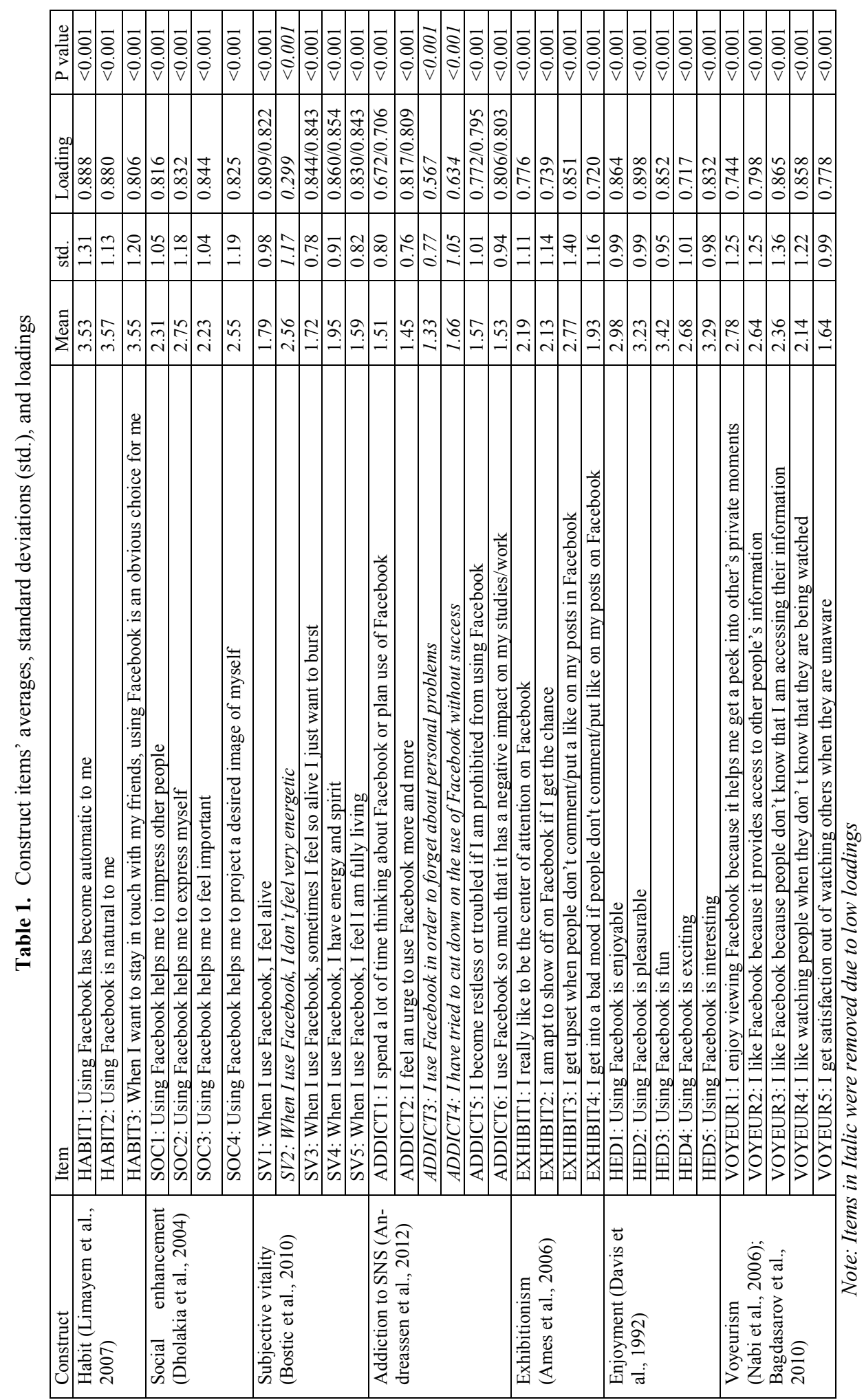


Discriminant validity refers to whether the items measure the construct in question or other (related) constructs (Gefen \& Straub, 2005). We verified discriminant validity using correlation matrix and factor analysis. Table 2 shows the correlation matrix with the square root of AVE values presented diagonally. The square root of the AVE value for the variables is consistently greater than the off-diagonal correlation values, suggesting satisfactory discriminant validity between the variables (Fornell \& Larcker, 1981). The "item to latent variable correlation" values obtained from the confirmatory factor analysis are shown in Table 3. It shows that all items have cross-loadings coefficients lower than the factor loading on their respective assigned latent variable, suggesting that discriminant validity on the item level is met for all the constructs (Gefen $\&$ Straub, 2005).

Overall, these tests of validity and reliability provided us with a high degree of confidence with the measures used in testing our research model. 


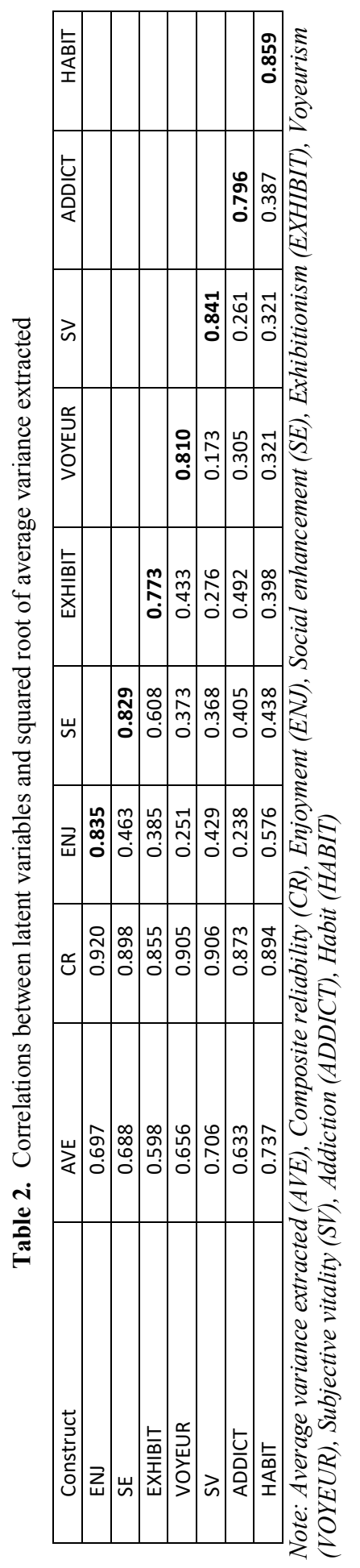

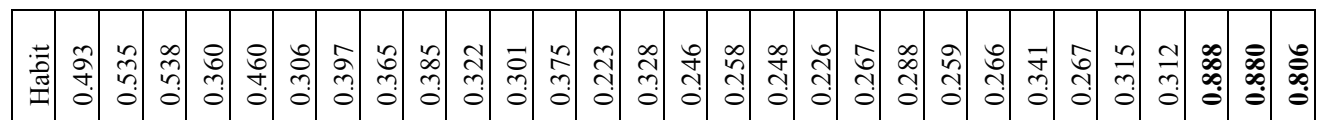

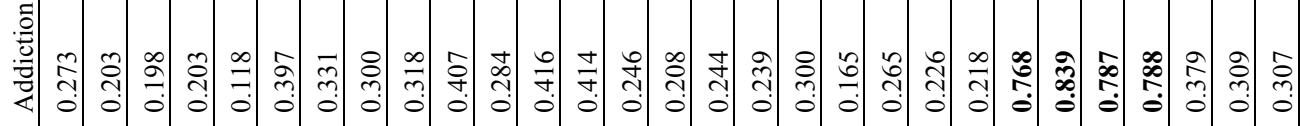

:

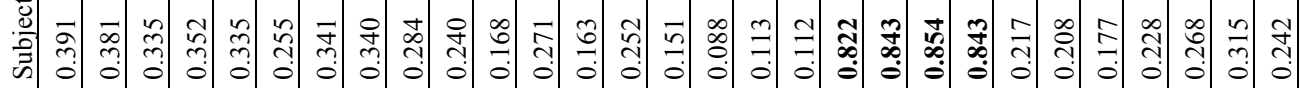

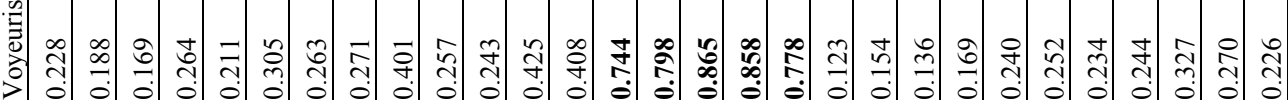

䓪

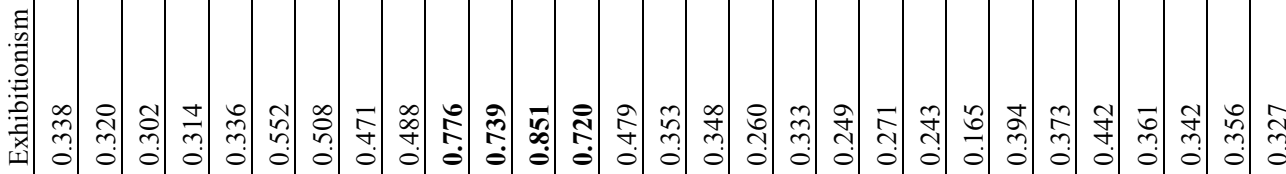

离

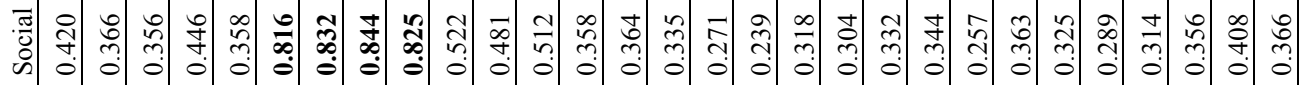

$\overrightarrow{\mathrm{s}}$

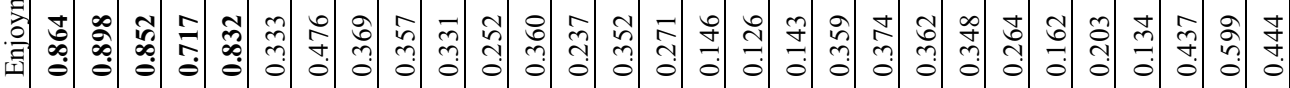

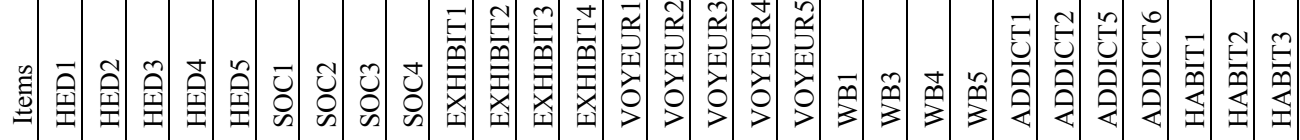




\section{$5 \quad$ Results and discussions}

\subsection{PLS results}

The test of the structural model includes estimates of the path coefficients, which indicate the strengths of the relationships between the dependent and independent variables, and the R-square values, which represent the amount of variance explained by the independent variables. Figure 2 shows the results of the hypothesized structural model.

As hypothesized, social enhancement $(\beta=0.20, \mathrm{p}<0.001)$ and perceived enjoyment $(\beta=0.31, p<0.001)$ had significant effect on subjective vitality after controlling the effect of habit on it. The explained amount variance of subjective vitality by its predictors was 23 per cent

Exhibitionism $(\beta=0.41, \mathrm{p}<0.001)$ had significant influence on addiction after controlling the influence of habit on it. Interestingly, voyeurism $(\beta=0.08, \mathrm{~ns})$ had no-significant influence on addiction. Taken together, the determinants explained 34 per cent of the variance in addiction.

\subsection{Key findings}

We point out to two observations that we think are the most interesting. First, we found that both social enhancement and enjoyment influence subjective vitality. This finding implies that an accurate presentation of one's image and enjoyment experienced by communicating and interacting with peers in an SNS improves one's subjective vitality. For example, when one receives positive feedback for the content he/she has posted (e.g., pictures, profile information, etc.), it may influence his/her subjective vitality. It also provides him/her pleasure. Additionally, surfing around in SNS for a while may offer a refreshing break and help one to feel more energetic.

Second, we found that exhibitionism significantly predicted addiction to SNS while controlling for the influence of habit. This may imply that exhibitionists frequently post content and check how many people comment or 'like' in their updates. In doing so, they may feel an urge to use the SNS more and more and eventually develop addiction. Interestingly, we also found that individuals' voyeuristic behaviours had non-significant influence on addiction to SNS. The reason behind the non-significant relationship can be explained by the fact that the SNS under investigation (i.e. Facebook) contains more features to support exhibitionistic behaviours and fewer features to support voyeuristic behaviours. Features like updating status, check-in, posting photos, etc. that supports exhibitionistic behaviours can be accessed easily in both desktop and mobile versions of Facebook. These features are integrated in mobile devices in such a way that individuals can execute these features with just few taps. In contrast, voyeuristic activities like finding a person from outside of one's friend list and viewing his/her content require much effort. Recently, Facebook has introduced the Graph Search feature that has eased the process of finding and accessing the content on Facebook. However, the Graph Search feature has not been included yet in the Facebook applications for mobile devices. Additionally, it is still not available for all (e.g. Finnish) Facebook 
users. Nevertheless, the Graph Search will most likely considerably increase the voyeuristic value of Facebook.

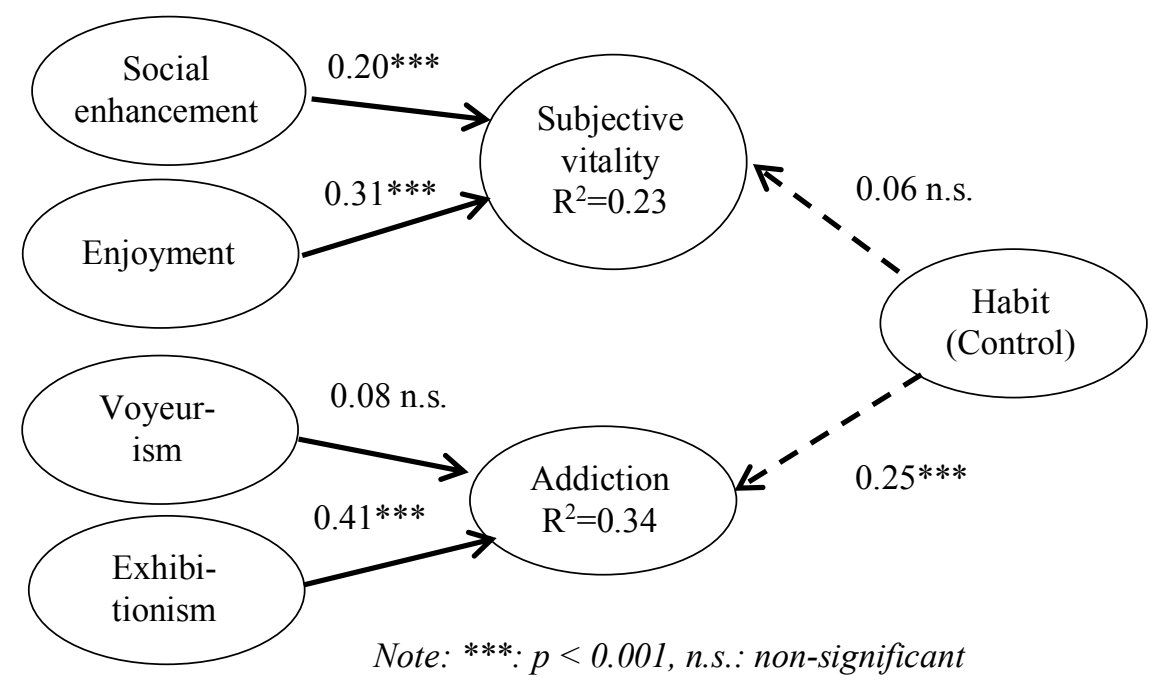

Figure . 2. PLS results

\subsection{Theoretical implications}

Our study has three theoretical implications for IS research. First, we advance the understanding of dual effect of IT. Prior IS research has mostly investigated either the positive (e.g. DeLone \& MacLean, 2003) or negative (e.g. Turel et al., 2011) effect of IT use. However, in this study we have shown that hedonic systems such as SNSs may lead to both positive and negative individual-level consequences. To this end, we included a benefit related variable (i.e., subjective vitality), and a danger related variable (i.e., addiction) in our research model as the dependent variables and examined their predictors.

Second, we accumulate the understanding of addiction in the SNS context. Prior IS research mostly implied that SNS enjoyment shapes habitual behaviour, which in turn leads to addiction (Turel \& Serenko, 2012). We found that exhibitionism is a significant predictor of addiction to SNSs after controlling the influence of habit. In fact, we found that the influence of exhibitionism on addiction was much stronger than that of habit.

Finally, drawing the concept of autonomous motivation (Deci \& Ryan, 1991), we hypothesized and empirically found that both social enhancement and enjoyment are significant predictors of subjective vitality. Despite its importance, prior IS research did not put enough effort investigating the concept of subjective vitality. We suggest future research investigating other autonomous motivations that influence subjective vitality. 


\subsection{Practical implications}

Our study has three practical implications. First, it should be remembered that IT may have dual effects on individuals. Using an SNS may both improve user's subjective vitality but also create addiction. In addition, to identifying the psycho-social predictors such as the variables employed in this study, understanding the dual effect of SNS's use requires also understanding the use patterns and use context. For example, taking short breaks from work and surfing SNSs may improve individual's subjective vitality, however, spending hours or frequent SNS surfing might lead to addiction. We hope that organizational and governmental decision-makers pay increased attention to the potential dual effects of IT in general and SNS in particular. We hope that the decisionmakers consider the possibility that the increased IT use is not mechanistically positive, and that all uses are not equally beneficial, or harmful.

Second, we found that individual's exhibitionistic behaviours cause addiction. SNSs contain many features for performing exhibitionistic behaviours. For example, status updates, pictures, likes and comments are some of the features that exhibitionists might utilize to show off. (Mäntymäki \& Islam, 2016; Islam et al., In Press). To reduce the risk of addiction, we slightly provocatively suggest that SNS providers and their legislative regulators would consider whether the exhibitionistic appeal of SNSs could be constrained. For example, the number of status updates or photos per day or month could be limited to a certain maximum to reduce the adverse effects and time spent on SNSs.

Finally, we found that an SNS use can be a source of subjective vitality improvement as it affords portraying one's appropriate image and offers hedonic value. Based on this finding, we suggest organizations that have categorically banned, and occasionally even tried to prevent SNS use in the workplace to reconsider this decision.

\section{$6 \quad$ Limitations and future research}

Our study has a number of limitations that may serve as the avenue for future research. First, the research was cross-sectional. The beliefs of the users regarding a system will change as the users gain experience of a target system but such changes cannot be captured with the type of cross-sectional study undertaken. Thus, longitudinal research is necessary to overcome the issue. Second, the study has been conducted using a single SNS (Facebook) in a single Finnish university. Hence, generalizing the findings directly to other user groups or other SNSs is not an appropriate course of action. Third, we included only a few drivers of subjective vitality and addiction. Future studies could incorporate a more extensive set of drivers of subjective vitality and addiction. Finally, yet we focused on subjective vitality and addiction to capture the dual effect of SNS use, these two constructs are by no means an exhaustive presentation of the possible positive and negative outcomes. Thus, future research could aim at identifying additional positive and negative outcomes of SNS use. 


\section{References}

1. Ackerman, R.A., Witt, E.A., Donnellan, M.B., Trzesniewski, K.H., Robins, R.W., \& Kashy, D.A. (2011). What does the narcissistic personality inventory really measure? Assessment, 18 (1), 67-87.

2. Akin, A. (2012). The relationship between Internet addiction, subjective vitality, and subjective happiness. Cyberpsychology, Behavior and Social Networking, 15(8), 404-410.

3. Ames, D. R., Rose, P., \& Anderson, C.P. (2006). The NPI-16 as a short measure of narcissism. Journal of Research in Personality, 40, 440-450.

4. Andreassen, C. S., Torsheim, T., Brunborg, G. S., \& Pallesen, S. (2012). Development of a Facebook addiction scale, Psychological Reports, 110 (2), 501-517.

5. Armstrong, J. S., \& Overton, T. (1977). Estimating nonresponse bias in mail surveys. Journal of Marketing Research, 14, 396-402.

6. Bagdasarov, Z., Greene, K., Banerjee, S. C., Krcmar, M., Yanovitzky, I., \& Ruginyte, D. (2010). I am what I watch: Voyeurism, sensation seeking, and television viewing patterns. Journal of Broadcasting \& Electronic Media, 54 (2), 299-315.

7. Barclay, D., Higgins, C., \& Thompson, R. (1995). The partial least squares (PLS) approach to causal modeling: Personal computer adoption and use as an illustration. Technology Studies, 2 (2), 285-324.

8. Barrett, J., Della-Maggiore, V., Chouinard, P. A., \& Paus, T. (2004). Mechanisms of action underlying the effect of repetitive transcranial magnetic stimulation on mood: Behavioral and brain imaging studies Neuropsychopharmacology, 29, 1172-1189.

9. Baruh, L. (2010). Mediated voyeurism and the guilty pleasure of consuming reality television. Media Psychology, 13 (3), 201-221.

10. Beard, K. (2005). Internet addiction: A review of current assessment techniques and potential assessment questions. CyberPsychology and Behavior, 8(1), 7-14.

11. Brown, R: I. F. (1993). Some contributions of the study of gambling to the study of other addictions. In W. R. Eadington \& J. Cornelius (Eds.), Gambling behavior and problem gambling. Reno, NV: University of Nevada Press. Pp. 341-372.

12. Block, J. J. 2008. Issues for DSM-V: Internet Addiction. American Journal of Psychiatry, 165 (3), 306-307.

13. Bostic, T. J., Rubio, D. M., \& Hood, M. (2000). A validation of the subjective vitality scale using structural equation modeling. Social Indicators Research, 52, 313-324.

14. Brunell, A. B., Staats, S., Barden, J., \& Hupp, J. M. (2011). Narcissism and academic dishonesty: The exhibitionism dimension and the lack of guilt. Personality and Individual Differences, 50 (3), 323-328.

15. Calvert, C. (2000). Voyeur nation: Media privacy, and peering in modern culture. Boulder, CO: Westview Press.

16. Carpenter, C. J. (2012). Narcissism on Facebook: Self-promotional and anti-social behaviour. Personality and Individual Differences, 52 (4), 482-486.

17. Charlton, J. P., \& Danforth, I. D. W. (2007). Distinguishing addiction and high engagement in the context of online game playing. Computers in Human Behavior, 23(3), 1531-1548.

18. Coleman-Kennedy, C., \& Pendley, A. (2002). Assessment and diagnosis of sexual addiction. Journal of the American Psychiatric Nurses Association, 8 (5), 143-151.

19. Davis, F. D. (1989). Perceived usefulness, perceived ease of use, and user acceptance of information technology. MIS Quarterly, 13 (3), 319-340.

20. Davis, F. D., Bagozzi, R. P., \& Warshaw, P.R. (1992). Extrinsic and intrinsic motivation to use computers in workplace. Journal of Applied Social Psychology, 22 (14), 1111-1132. 
21. Davis, R. A. Flett G. L., \& Besser A. (2002). Validation for a new scale for measuring problematic internet use: Implications for pre-employment screening. Cyberpsychology \& Behavior, 5 (4), 331-345.

22. De Charms, R. (1968). Personal Causation: The internal affective determinants of behaviour. Academic Press: New York.

23. Deci, E. L., \& Ryan, R. M. (1991). A motivational approach to self: Integration in personality. In R. Dienstbier (Ed.), Nebraska Symposium on Motivation: Vol. 38. Perspectives on motivation (pp. 237-288). Lincoln: University of Nebraska Press.

24. DeLone, W. H., \& McLean, E. R. (2003). The DeLone and McLean model of information systems success: A ten year update. Journal of Management Information Systems, 19 (4), 9-30.

25. Dholakia, U. M., Bagozzi, R. P., \& Pearo, L. K. (2004). A social influence model of consumer participation in network- and small-group-based virtual communities. International Journal of Research in Marketing, 21, 241-261.

26. Douglas, A. C., Mills, J. E., Niang, M., Stepchenkova, S., Byun, S., Ruffini, C., Lee, S. K., Loutfi, J., Lee, J.-K., Atallah, M., \& Blanton, M. (2008). Internet addiction: Meta-synthesis of qualitative research for the decade 19996-2006. Computers in Human Behavior, 24, 3027-3044.

27. Fornell, C., \& Larcker, D. F. (1981). Evaluating structural equation models with unobservable variables and measurement error. Journal of Marketing Research, 18 (1), 39-50.

28. Gefen, D., \& Straub, D. (2005). A practical guide to factorial validity using PLS-Graph: Tutorial and annotated example. Communications of the Associations for Information Systems, 16 (5), 91-109.

29. Griffiths, M. D. (1995). Technological addictions. Clinical Psychology Forum, 95, 14-19.

30. Griffiths, M. D. (2005). A "components" model of addiction within a bio-psychosocial framework. Journal of Substance Use, 10, 191-197.

31. Hars, A., \& Ou, S. (2002). Working for free? Motivations for participating in open-source projects. International Journal of Electronic Commerce, 6 (3), 23-37.

32. Hirschfeld, M. (1938). Sexual anomalies and perversions: Physical and psychological development, diagnosis and treatment (new and revised edition). London: Encyclopaedic Press.

33. Hollenbaugh, E. E., \& Ferris, A. L. (2014). Facebook self-disclosure: Examining the role of traits, social cohesion, and motives. Computers in Human Behavior, 30, 50-58.

34. Horvath, S. \& Morf, C. C. (2010). To be grandiose or not to be worthless: Different routes to self-enhancement for narcissism and self-esteem. Journal of Research in Personality, 44, 585592.

35. Islam, A.K.M.N., Mäntymäki, M. \& Benbasat, I. (In Press). Duality of self-promotion on social networking sites, Information Technology \& People.

36. Joinson, A.N., Paine, C., Buchanan, T., \& Reips, U. (2008). Measuring self-disclosure online: Blurring and non-response to sensitive items in web-based surveys. Computers in Human Behavior, 24 (5), 2158-2171.

37. Jourard, S.M., \& Lasakow, P. (1958). Some factors in self-disclosure. Journal of Abnormal and Social Psychology, 56 (1), 91-98.

38. Koopman, F. \& Sremac, S. (2011). Addiction and Autonomy: Are addicts autonomous? Nova Prisutnost, 9 (1), 171-188.

39. Kubey, R., \& Csikszentmihalyi, M. (2002). Television addiction is no mere metaphor. Scientific American, 286, 74-80.

40. Kuss, D. J. \& Griffiths, M. D. (2011). Addiction to social networks on the Internet: A literature review of empirical research. International Journal of Environment and Public Health, 8 (9), 3528-3552.

41. Kuss, D. J. \& Griffiths, M. D. (2012). Social networking on the Internet: From pastime to excess and addiction. Mental Notes, 6 (3), 26-28. 
42. Limayem, M., Hirt, S. G., \& Cheung, C. M. K. (2007). How Habit Limits The Predictive Power Of Intention: The Case of Information Systems Continuance. MIS Quarterly, 31 (4), 705-737.

43. Marks, I. (1990). Behavioural (non-chemical) addictions. British Journal of Addiction, 85 (11), 1389-1394.

44. Marlatt, G., Baer, J., Donovan, D., \& Kivlahan, D. (1988). Addictive behaviors: Etiology and treatment. Annual Review of Psychology, 39, 223-252.

45. McCaslin, M. J., Petty, R. E. \& Wegener, D. T. (2010). Self-enhancement and theory-based correction processes. Journal of Experimental Social Psychology, 46, 830-835.

46. McNair, D., Lorr, M., \& Droppleman, L. (1971). Profile of Mood States. San Diego, CA: Ed ITS/Educational and Industrial Testing Service.

47. Metzl, Jonathan M. (2004). "Voyeur Nation? Changing Definitions of Voyeurism, 1950-2004". Harvard Review of Psychiatry 12 (2): 127-31.

48. Moore, G. C., \& Benbasat, I. (1991). Development of an instrument to measure the perception of adopting an Information Technology innovation. Information Systems Research, 2 (3), 192222.

49. Mitchell, P. (2000). Internet addiction: Genuine diagnosis or not? The Lancet, 355(9204).

50. Munar A. M. (2010). Digital exhibitionism: The age of exposure. Cultural Unbound, 2, 401422.

51. Mäntymäki, M. \& Islam, A.K.M.N. (2014). Voyeurism and Exhibitionism as gratifications from Prosuming Social Networking sites. In Proceedings of the 22nd European Conference on Information Systems (ECIS2014), Tel Aviv, Israel, 9 -11 June 2014.

52. Mäntymäki, M., \& Islam, A.K.M.N . The Janus face of Facebook: Positive and negative sides of social networking site use. Computers in Human Behavior 61(8): 14-26.

53. Nabi, R. L., Stitt, C. R., Halford, J. \& Finnerty, K. L. (2006). Emotional and cognitive predictors of the enjoyment of reality-based and fictional television programming: An elaboration of the uses and gratifications perspective. Media Psychology, 8 (4), 421-447.

54. Nix, G. A., Ryan, R. M., Manly, J. B., \& Deci, E. L. (1999). Revitalization through self-regulation: The effects of auton omous and controlled motivation on happiness and vitality. Journal of Experimental Social Psychology, 35, 266-284.

55. Nunnally, J. C. (1978). Psychometric theory. McGraw Hill: New York.

56. Panek, E.T., Nardis, Y., \& Konrath, S. (2013). Mirror or megaphone?: How relationships between narcissism and social networking site use differ on Facebook and twitter. Computers in Human Behavior, 29 (5), 2004-2012.

57. Penninx, B. W. J. H., Guralnik, J. M., Bandeen-Roche, K., Kasper, J. D., Simonsick, E. M., Ferrucci, L. (2000). The protective effect of emotional vitality on adverse health outcomes in disabled older women. Journal of American Geriatric Society, 48 (11), 1359-1366.

58. Raskin, R., \& Terry, H. (1988). A principal-components analysis of the narcissistic personality inventory and further evidence of its construct validity. Journal of personality and social psychology, 54 (5), 890.

59. Rice, M. (2005). Online addiction. Beijing Review, 48(46), 32-33.

60. Roller, C. G. (2004). Sex addiction and women: A nursing issue. Journal of Addictions Nursing, $15,53-61$.

61. Ryan, R. M. and Frederick, C. (1997). On energy, personality, and health: Subjective vitality as a dynamic reflection of well-being. Journal of Personality, 65, 529-565.

62. Ryan, R. M., \& Deci, E. L. (2001). To be happy or to be self-fulfilled: A review of research on hedonic and eudaimonic well-being. In S. Fiske (Ed.), Annual Review of Psychology (Vol. 52; pp. 141-166). Palo Alto, CA: Annual Reviews, Inc. 
63. Ryan, R. M. and Deci, E. L. (2008). From ego depletion to vitality: Theory and energy findings concerning the facilitation of energy available to the shelf. Social and Personal Psychology Compass, 2(2), 702-717.

64. Shapira, N. A., Goldsmith, T. G., Keck, P. E. Jr., Khosla, U. M., \& McElroy, S. L. (2000). Psychiatric features of individuals with problematic internet use. Journal of Affective Disorders, 57, 267-272.

65. Shapira, N. A., Lessig, M. C., Goldsmith, T. D., Szabo, S. T., Lazoritz, M., Gold, M. S., \& Stein, D. J. (2003). Problematic Internet use: Proposed classification and diagnostic criteria. Depression and Anxiety, 17(4), 207-216.

66. Silverstein, J. (1996). Exhibitionism as countershame. Sexual Addiction and Compulsivity, 3 (1), 33-42.

67. Taylor, S. E., \& Brown, J. D. (1989). Illusion and well-being: A social psychological perspective on mental health. Psychological Bulletin, 103 (2), 193-210.

68. Thayer, R. E. (1996). The Origin of Everyday Moods. New York, NY: Oxford University Press.

69. Turel, O., \& Serenko, A. (2012). The benefits and dangers of enjoyment with social networking websites. European Journal of Information Systems, 21(5), 512-528.

70. Turel, O., Serenko, A., \& Giles, P. (2011). Integrating Technology Addiction and Use: An Empirical Investigation of Online Auction Users. MIS Quarterly, 35(4), 1043-1051.

71. Van der Heijden, H. (2004). Acceptance of hedonic Information Systems. MIS Quarterly, 28 (4), 695-704.

72. Valkenburg, P., Peter, J., \& Schouten, A. (2006). Friend networking sites and their relationship to adolescents' well-being and social self-esteem. CyberPsychology \& Behavior, 9, 584-590.

73. Venkatesh, V. (2000). Determinants of perceived ease of use: integrating control, intrinsic motivation, and emotion into the technology acceptance model. Information Systems Research, 11 (4), 342- 365

74. Venkatesh, V., \& Davis, F. D. (2000). A theoretical extension of the technology acceptance model: Four longitudinal field studies. Management Science, 46 (2), 186-204.

75. Venkatesh, V., Thong, J. Y. L., \& Xu, X. (2012). Consumer acceptance and use of information technology: Extending the unified theory of acceptance and use of technology. MIS Quarterly, $36(1), 157-178$.

76. Watson, D., \& Tellegen, A. (1985). Toward a consensual structure of mood. Psychological Bulletin, 98, 219-235.

77. Widyanto, L., \& Griffiths, M. D. (2006). Internet addiction: A critical review. International Journal of Mental Health and Addiction, 4, 31-51.

78. Xu, Z., Turel, O., \& Yuan, Y. (2012). Online game addiction among adolescents: Motivation and prevention factors. European Journal of Information Systems, 21, 321-340.

79. Young, K. S. (1996). Internet addiction: The emergence of a new clinical disorder. Paper presented at the the 104th annual meeting of the American Psychological Association, Toronto, Canada.

80. Young, K. S. (1998). Internet addiction: The emergence of a new clinical disorder. CyberPsychology \& Behavior, 1, 237-244.

81. Young, K. (2010). Internet addiction over the decade: A personal look back. World Psychiatry, 9 (2), 91-91.

82. Yellowlees, P. M., and Marks, S. (2007). Problematic Internet Use or Internet Addiction?, Computers in Human Behavior, 23 (3), 1447-1453. 